\title{
Pelatihan Tugas Perawatan Kesehatan Keluarga Caregiver Lansia dalam Pogram RURAL (Rumah Ramah Lansia)
}

\author{
Annisa Wuri Kartika*, Muladefi Choiriyah, Niko Dima Kristianingrum, Linda W. Noviyanti, \\ Endah Panca Lidya Fatma \\ Jurusan Keperawatan Fakultas Kedokteran Universitas Brawijaya Jl. Veteran Malang \\ Jawa Timur 65145 \\ *annisa_tika@ub.ac.id
}

Submisi: 18 April 2019; Penerimaan: 25 November 2019

\begin{abstract}
Tata K(unci:. Abstrak Penurunan fungsi akibat penuaan yang disertai dengan masalah kesehatan perawatan lansia di rumah; kemampuan perawatan caregiver; penyakit kronis. pada lansia berdampak pada kemampuan lansia dalam melakukan activity daily living (ADL) dan kemandirian perawatan kesehatannya. Peran keluarga sebagai caregiver sangat penting dalam memberikan perhatian dan bantuan perawatan kesehatan pada lansia. Kemampuan dan keterampilan caregiver yang disertai dengan kesiapan lingkungan menjadi faktor penting dalam perawatan lansia sakit kronis di rumah. Kegiatan pengabdian masyarakat ini bertujuan untuk meningkatkan kemampuan caregiver dalam memberikan perawatan pada lansia dengan penyakit kronis di rumah. Bentuk kegiatan adalah RURAL (Rumah Ramah Lansia), yaitu mewujudkan lingkungan rumah yang sesuai untuk lansia sakit, baik dalam hal lingkungan fisik maupun psikososial. Hal ini diwujudkan dengan melatih keluarga lansia sebagai caregiver terkait keterampilan perawatan lansia di rumah. Kegiatan dilaksanakan di RW 4 Kelurahan Jatimulyo, Kota Malang pada Januari-Maret 2018. Metode yang digunakan adalah pendidikan kesehatan, pelatihan keterampilan perawatan, serta supervisi dengan home visit. Hasil kegiatan ini adalah 70 persen keluarga memiliki kemampuan baik dalam menjalankan lima tugas perawatan kesehatan keluarga; pengetahuan mengenai perawatan lansia di rumah sudah baik dengan nilai rata-rata pengetahuan 8,6. Dari hasil tersebut dapat disimpulkan bahwa kegiatan pelatihan perawatan lansia dengan sakit kronis di rumah bermanfaat untuk meningkatkan kemampuan caregiver dalam meningkatkan status kesehatan lansia.
\end{abstract}

Keywords: $\quad$ Abstract The decline in function due to aging accompanied by health problems in elderly care at the elderly has an impact on the ability of the elderly in activity daily living ( $A D L)$ home; caregiver care ability; chronic and health care. The role of the family is very important in health care assistance to the elderly. Caregiver skills accompanied by environmental aspect are important factors for elderly with chronic illness at home. This community service aims to improve the caregiver's ability to provide care to the elderly with chronic illness. RURAL (Rumah Ramah Lansia) is activity to create a suitable environment for the elderly in terms of physical and psychosocial environment. The families trained as a caregivers which are carried out in RW 4, Jatimulyo, Malang City in January March 2018. The activities of the program is health education and skill training about caring for elderly. The results are 70 percent of families have good ability in carrying out family health care tasks; knowledge about elderly care at home is good with an average knowledge value of 8.6. From these results it can be concluded that training for caregivers is useful to improve the ability of caregivers and health status of the elderly. 


\section{PENDAHULUAN}

Jumlah lansia di Indonesia pada 2018 mencapai 9,27\% atau sekitar 24,49 juta jiwa dari keseluruhan jumlah penduduk. Berdasarkan data proyeksi diketahui bahwa lansia di Indonesia akan meningkat 2,5 kali lipat pada 2045 dari jumlah lansia tahun 2018. Persentase lansia di Indonesia didominasi oleh lansia muda (kelompok umur 60 s.d. 69 tahun) sebesar 63,39\%, sisanya adalah lansia madya (kelompok umur 70 s.d. 79 tahun) sebesar 27,92\%, dan lansia tua (kelompok umur 80+) sebesar 8,69\% (Badan Pusat Statistik, 2018). Adapun jumlah lansia di Jawa Timur mencapai 12,64\% pada 2018 dan akan mencapai 13,48\% pada 2020 menurut proyeksi (BPS Provinsi Jawa Timur, 2019). Pertumbuhan lansia yang cukup signifikan tersebut memberikan tantangan dalam bidang layanan kesehatan karena meningkatnya penyakit degeneratif dan masalah kesehatan lainnya sehingga berimbas pada peningkatan biaya kesehatan.

Lansia pada umumnya mengalami berbagai gejala akibat penurunan fungsi biologis, psikologis, sosial, dan ekonomi. Persentase lansia yang sakit pada 2018 sebesar 25,99\%. Keluhan yang dilaporkan meningkat seiring usia dalam sebulan terakhir. Sebanyak 51,48\% lansia madya mengalami keluhan kesehatan dan jumlah itu meningkat menjadi 54,98\% pada penduduk lansia tua (BPS, 2018). Hasil Riset Kesehatan Dasar (Riskesdas) tahun 2018 menunjukkan bahwa prevalensi lansia dengan penyakit tidak menular (PTM) didominasi oleh penyakit kardiovaskular, yaitu hipertensi dan strok serta penyakit lain, antara lain diabetes, kanker, serta nyeri sendi (Kemenkes, 2018). Lansia di atas usia 85 tahun cenderung memiliki masalah risiko jatuh, penyakit kardiovaskular, osteoporosis, demensia, dan ketergantungan dalam activity daily living (ADL) (Jaul \& Barron, 2017). Berdasarkan hasil Proyeksi Penduduk Hasil Perbaikan Supas 2015 (BPS, 2018), rasio ketergantungan penduduk lansia di Jawa Timur pada 2017 sebesar 19,68. Hal itu berarti bahwa setiap 100 orang penduduk usia produktif menanggung sekitar 19 hingga 20 orang penduduk lansia. 
Keluarga berperan penting dalam mendukung perawatan lansia sakit, manajemen pengobatan lansia, peningkatan kualitas hidup lansia, serta dalam memenuhi aktivitas sehari-hari, termasuk status kesehatan lansia (Rosland, 2009). Shresta et al. (2018) dalam penelitiannya menyampaikan bahwa kualitas hidup lansia yang tinggal bersama keluarga lebih baik daripada lansia yang tinggal di nursing home. Hasil penelitian Amigo (2012) mengenai pelaksanaan tugas perawatan kesehatan keluarga dengan status kesehatan lansia berupa hipertensi di Yogyakarta menyebutkan bahwa ada hubungan antara pelaksanaan tugas perawatan kesehatan keluarga dengan status kesehatan lansia dan dengan sakit hipertensi. Sebagian besar lansia di Indonesia tinggal bersama keluarga besarnya, yaitu 43,18 \% tinggal bersama tiga generasi dalam satu rumah tangga dan 27,03\% tinggal bersama keluarga inti atau pasangannya. Oleh karena itu, peran keluarga sangat penting dalam memberikan perhatian dan bantuan perawatan kesehatan pada lansia.

Keluarga sebagai caregiver utama memiliki peran dalam fungsi perawatan kesehatan lansia di rumah. Peran dan tanggung jawab ini melibatkan seluruh aspek, yaitu fisik, psikologis, emosional, sosial, dan finansial (Friedman, Bowden, \& Jones, 2010). Penelitian Asniar (2007) dan Wiyono (2007) pada caregiver yang berada di wilayah Kota Depok menunjukkan bahwa beban fisik, mental, dan materi yang muncul akibat merawat anggota keluarga dengan penyakit kronis dapat menimbulkan koping maladaptif yang salah satunya adalah upaya penghentian pengobatan dan pengabaian. Keluarga sebagai pemberi asuhan dalam merawat lansia harus memiliki pengetahuan yang baik dalam menjalankan perannya sebagai caregiver.

Program dukungan psikososial pada keluarga sebagai caregiver dipandang penting untuk menurunkan terjadinya pengabaian pada lansia. Hal ini seperti yang terjadi di Korea. Beban ekonomi, beban perawatan, kurangnya informasi, dan kurangnya dukungan sosial berhubungan erat dengan pengabaian lansia yang dilakukan 
caregiver lansia di Korea (Lee, 2008). Dukungan kepada keluarga yang berperan sebagai caregiver lansia yang berupa pemberian informasi dan pendampingan sangat penting untuk meningkatkan partisipasi keluarga dan menurunkan burden yang dialami keluarga (Pahlavanzadeh et al., 2010). Kebutuhan informasi mengenai manajemen pengobatan, pola pengaturan nutrisi, strategi koping, ambulasi, dan dukungan dari kelompok di lingkungan sangat diperlukan oleh keluarga untuk meningkatkan kualitas manajemen perawatan kepada lansia yang dirawat (Alvarez et al., 2017). Oleh karena itu, peran pelatihan manajemen perawatan lansia di rumah merupakan salah satu bentuk upaya meningkatkan kualitas perawatan lansia sakit.

Kementerian sosial mengeluarkan Permensos RI No. 4 Tahun 2017 tentang Pedoman Pengembangan Kawasan Ramah Lanjut Usia sebagai acuan dalam pengembangan kawasan ramah lanjut usia bagi pemerintah, masyarakat, dan dunia usaha. Hal tersebut bertujuan untuk mendukung kebutuhan serta pemenuhan hak lansia dalam mewujudkan lansia yang mandiri, sehat, aktif, dan produktif. Sejalan dengan program tersebut, kegiatan pengabdian masyarakat RURAL (Rumah Ramah Lansia) dilaksanakan sebagai salah satu program untuk meningkatkan kualitas hidup lansia sakit yang dirawat oleh keluarga di rumah. Kegiatan ini dilakukan dengan sasaran keluarga yang merawat lansia serta kader kesehatan posyandu lansia dengan memberikan pelatihan manajemen perawatan lansia sakit di rumah. Program pelatihan ini diharapkan akan dapat menjadi salah satu upaya dalam peningkatan kualitas hidup lansia.

\section{MASALAH}

Kelurahan Jatimulyo merupakan salah satu wilayah di Kecamatan Kendalsari, Kota Malang, Provinsi Jawa Timur yang memiliki posyandu lansia aktif. Posyandu lansia di RW 04 memiliki jumlah lansia 109 orang. Jumlah lansia muda (60 s.d. 69 tahun) sebanyak $81 \%$ dan $19 \%$ lainnya adalah lansia madya (71 s.d. 80 tahun). Kehadiran lansia dalam setiap pelaksanaan posyandu rata-rata 30 s.d. 40 orang atau (27\% s.d. 
36\%). Sebagian besar lansia yang tidak pernah datang ke posyandu lasia di antaranya menyatakan bahwa ketidakhadirannya disebabkan oleh kondisi sakit yang tidak memungkinkan untuk datang ke posyandu; lansia bekerja pada saat posyandu dilaksanakan; dan tidak ada keluarga yang mengantar ke posyandu. Posyandu lansia merupakan pusat kegiatan masyarakat untuk meningkatkan jangkauan pelayanan kesehatan lansia. Ketidakhadiran lansia pada kegiatan ini membuat mereka tidak mendapatkan layanan kontrol kesehatan secara rutin. Faktor lain yang menghambat pelayanan kesehatan pada lansia adalah terbatasnya kemampuan kader kesehatan dalam menjalankan tugasnya. Hal tersebut membuat lansia dengan keluhan sakit yang tidak bisa datang ke posyandu menjadi tidak tertangani.

Berdasarkan data pendahuluan diketahui bahwa keluhan terbanyak yang dialami lansia adalah masalah nyeri sendi, yaitu 37\%; sering kesemutan dan pusing 29\%; rabun $12 \%$; riwayat strok $4 \%$; dan sebanyak $4 \%$ menggunakan alat bantu jalan. Sebanyak $68 \%$ lansia di wilayah tersebut tinggal bersama keluarga, 24\% tinggal dengan pasangan, dan 8\% tinggal sendiri. Dari hasil studi pendahuluan diketahui bahwa 20\% lansia memiliki riwayat hipertensi, 24\% penyakit sesak serta kolesterol tinggi, dan 9\% dengan DM. Sebagian besar lansia yang tinggal di keluarga tidak lagi memasak makanannya sendiri, sedangkan keluarga mereka sebagian besar tidak tahu perihal manajemen nutrisi yang tepat bagi lansia dengan penyakit kronis. Pihak keluarga mengatakan bahwa mereka belum pernah mendapatkan pelatihan khusus mengenai perawatan lansia dengan sakit kronis di rumah.

Keluarga menjadi sumber pendukung utama bagi perawatan lansia, khususnya lansia yang sakit. Keluarga yang mampu memahami peran dalam perawatan lansia serta memiliki keterampilan perawatan diharapkan akan melaksanakan tugas perawatan kesehatan secara optimal dan meningkatkan partisipasi lansia dalam kontrol kesehatan, baik pada kegiatan posyandu maupun layanan kesehatan di puskesmas. 


\section{METODE}

\subsection{Metode Pelaksanaan Kegiatan Pengabdian Masyarakat}

Kegiatan pengabdian masyarakat ini menggunakan metode pendidikan kesehatan mengenai materi perawatan lansia sakit di rumah dan pelatihan keterampilan perawatan serta pendampingan perawatan dengan metode home visit. Kegiatan ini bertujuan untuk memberikan keterampilan pada keluarga dan menyiapkan lingkungan rumah yang dapat mendukung proses perawatan lansia dengan penyakit kronis sehingga tercipta Rumah Ramah Lansia (RURAL). Kader kesehatan posyandu lansia juga dilibatkan sebagai pendukung di komunitas tempat keluarga tinggal.

Kegiatan pendidikan kesehatan yang dilaksanakan untuk keluarga diisi dengan materi mengenai konsep penuaan dan lima penyakit kronis yang ada pada lansia berdasarkan hasil pengkajian awal, yaitu hipertensi, Diabetes Mellitus, Osteoarthtis, strok, dan asam urat. Kegiatan ini menggunakan metode ceramah dan tanya jawab. Pendidikan keterampilan perawatan yang dilaksanakan berupa kegiatan pelatihan perawatan yang mencakup cara manajemen nutrisi bagi lansia dan senam perawatan kaki diabetes untuk lansia serta senam keseimbangan yang dapat diberikan kepada lansia. Materi lain yang juga disampaikan adalah perihal lingkungan rumah yang aman untuk lansia. Metode yang digunakan adalah demo, diskusi, dan tanya jawab. Di akhir kegiatan, peserta akan diberi buku panduan perawatan lansia dengan sakit kronis di rumah yang berisi penjelasan mengenai penyakit pada lansia, teknik ambulasi, kegiatan senam untuk lansia, perawatan lansia bed-rest, serta manajemen koping dan stres untuk caregiver. Pendampingan perawatan lansia dilakukan dengan kegiatan home visit pada keluarga yang menjadi caregiver dan lansia yang telah mengikuti kegiatan pelatihan. Home visit dilakukan untuk mengontrol kesehatan lansia dan menanyakan kesulitan serta hambatan yang dialami caregiver saat melakukan tugas perawatan. 


\subsection{Teknik Pengumpulan dan Analisa Data}

Teknik pengumpulan data dilakukan dengan post-test observasi dan wawancara. Posttest digunakan untuk mengukur pengetahuan peserta setelah mengikuti kegiatan pelatihan. Adapun teknik observasi digunakan pada saat mengevaluasi kemampuan peserta ketika mempraktikkan kegiatan senam perawatan kaki dan senam stabilitas yang diberikan. Teknik pengambilan data lainnya adalah wawancara untuk menggali data subjektif peserta kegiatan, yakni mengidentifikasi kesulitan dan hambatan selama melakukan tugas perawatan. Data yang diperoleh kemudian dianalisis dan dideskripsikan secara naratif.

\subsection{Lokasi, Waktu, dan Lama Kegiatan}

Kegiatan pengabdian masyarakat ini dilaksanakan selama satu bulan, yakni sejak Januari s.d. Maret 2018. Tempat pelaksanaan kegiatan adalah wilayah posyandu lansia RW 04 Kelurahan Jatimulyo, Malang, Jawa Timur. Kegiatan ini diikuti oleh sembilan belas keluarga yang menjadi caregiver lansia dan delapan kader posyandu lansia. Jumlah lansia yang terdata, yakni yang memiliki sakit kronis dan dirawat di rumah sebanyak 32 lansia dengan satu caregiver yang mampu merawat satu atau dua lansia dalam satu rumah.

\section{HASIL DAN PEMBAHASAN}

Keluarga yang berperan sebagai caregiver lansia dengan sakit kronis di rumah lebih banyak yang memiliki hubungan dekat dengan lansia, yaitu pasangan atau anak perempuan. Karakteristik perawatan dan tugas perawatan yang dilakukan oleh keluarga dapat dilihat pada data Tabel 1.

Berdasarkan data tersebut diketahui bahwa keluarga yang berperan sebagai caregiver, yakni sebanyak 7 orang (37\%) merupakan istri dan sebanyak 7 orang (37\%) merupakan anak. Adapun sisanya adalah menantu, keponakan, cucu, atau saudara 
perempuan. Caregiver lansia sebagian besar berjenis kelamin perempuan, yaitu 18 orang (94\%) dan sebagian besar sudah tinggal dengan lansia antara 30 s.d. 40 tahun, yaitu 7 orang (37\%). Tugas perawatan yang dilakukan oleh caregiver, yaitu 12 orang (63\%) sebagian besar adalah menyiapkan makan dan manajemen pengobatan dengan lama perawatan 4 s.d. 8 jam/hari. Sebagian besar lansia dari 32 lansia yang dirawat memiliki keluhan nyeri sendi, lemas, dan pusing. Adapun sebagian besar yang lain memiliki kemampuan ADL mandiri, yakni 17 orang (53\%) dan 3 orang lansia (9\%) lainnya memiliki kemampuan ADL yang harus dibantu total.

Tabel 1. Karakteristik Demografi Caregiver Lansia

\begin{tabular}{|c|c|c|c|}
\hline No. & Karakteristik Responden $(\mathrm{n}=19)$ & Jumlah & Persentase \\
\hline 1. & Usia (tahun, mean $\pm \mathrm{sd}$ ) & \multicolumn{2}{|c|}{$47,56 \pm 13,45$} \\
\hline \multirow{3}{*}{2.} & Kelamin & & \\
\hline & Pria & 1 & 5.5 \\
\hline & Wanita & 18 & 94.5 \\
\hline \multirow[t]{5}{*}{3.} & Pendidikan & & \\
\hline & SD & 8 & 42,1 \\
\hline & SMP & 1 & 5.5 \\
\hline & SMA & 8 & 42.1 \\
\hline & Sarjana & 2 & 10.3 \\
\hline \multirow[t]{4}{*}{4.} & Pekerjaan & & \\
\hline & Tidak bekerja/IRT & 14 & 73.6 \\
\hline & Pedagang & 2 & 10.5 \\
\hline & Pegawai & 3 & 15.9 \\
\hline \multirow[t]{2}{*}{5.} & Agama & & \\
\hline & Islam & 19 & 100 \\
\hline \multirow[t]{6}{*}{6.} & Lama Tinggal dengan Lansia & & \\
\hline & $0-10$ tahun & 6 & 31.5 \\
\hline & $>10-20$ tahun & 0 & 0 \\
\hline & $>20-30$ tahun & 1 & 5.5 \\
\hline & $>30-40$ tahun & 7 & 36.8 \\
\hline & $>40$ tahun & 5 & 26.2 \\
\hline \multirow[t]{4}{*}{7.} & Hubungan dengan Lansia & & \\
\hline & Istri & & \\
\hline & Anak & & \\
\hline & Lain-lain & 14 & 43.8 \\
\hline \multirow[t]{4}{*}{8.} & Bantuan Perawatan & & \\
\hline & Manajemen obat & 4 & 21 \\
\hline & Masak, makan, obat & 12 & 63.1 \\
\hline & Semua ADL & 3 & 15.9 \\
\hline \multirow[t]{4}{*}{9.} & Lama Melakukan Perawatan & & \\
\hline & $1-3 \mathrm{jam} / \mathrm{hari}$ & 5 & 26.2 \\
\hline & $3-8 \mathrm{jam} / \mathrm{hari}$ & 2 & 10.7 \\
\hline & $>8 \mathrm{jam} / \mathrm{hari}$ & 12 & 63.1 \\
\hline
\end{tabular}

Sumber: Data primer diolah (2018) 
Keluarga dengan lansia yang menderita sakit kronis merupakan populasi berisiko yang disebabkan karena proses adaptasi mereka untuk menyesuaikan diri dengan tugas perawatan dapat merubah homeostasis keluarga. Tuntutan baru yang muncul dalam keluarga yaitu bertambahnya peran perawatan dapat merubah perilaku, struktur, komunikasi, peran, dan fungsi dalam keluarga (Friedman et.al, 2010). Hal tersebut memberikan dampak pada kesehatan fisik, sosial maupun psikologis anggota keluarga.

Perubahan peran dalam keluarga akibat adanya penderita sakit kronis dalam keluarga yaitu peran sebagai caregiver. Peran ini menuntut keluarga untuk mempelajari keterampilan baru dalam merawat anggota keluarga yang sakit dan perubahan gaya hidup (misalnya pola makan mengikuti aturan diet yang ditetapkan bagi anggota keluarga yang sakit). Selain hal tersebut, perubahan juga terjadi pada aktivitas tidur dan istirahat karena tugas perawatan serta perubahan aktivitas rekreasi dan hobi yang tidak bisa lagi dilakukan karena prioritas utama keluarga adalah merawat anggota keluarga yang sakit.

Peran caregiver lebih banyak dilakukan oleh keluarga yang memiliki hubungan kekeluargaan dengan penderita (Schulz \& Martire, 2004). Caregiver bisa terdiri atas pasangan suami dan istri, anak, cucu, atau ibu pada anak-anak dengan penyakit kronis. Selain itu, peran caregiver juga dipengaruhi oleh konteks budaya yang memandang bahwa peran caregiver lebih utama dilakukan oleh perempuan (Gopalan \& Brannon, 2006). Penelitian Goldzweig et al. (2012) mengenai koping pada pasien kanker mengidentifikasi bahwa $40 \%$ caregiver dilakukan oleh pasangan dan $66 \%$ dilakukan oleh perempuan. Adapun penelitian Arbaiyah (2008) mengenai caregiver pada penderita penyakit mental di Aceh, Indonesia menyebutkan bahwa peran caregiver sebanyak 63,85\% dilakukan oleh perempuan. 
Tugas-tugas yang dilaksanakan oleh caregiver salah satunya adalah membantu penderita dalam aktivitas sehari-hari (ADL), yaitu mandi, makan, mobilisasi, dan membantu manajeman pengobatan serta perawatan penyakitnya (Spillman et al., 2014; Wolff et al., 2016). Kegiatan ADL dilakukan karena lansia mengalami keterbatasan atau sudah tidak mampu lagi melakukan secara mandiri. Sebanyak 44\% keluarga melaporkan bahwa mereka membantu kegiatan tersebut hampir setiap hari.

Setelah dilakukan pelatihan, pengetahuan dan keterampilan perawatan lansia yang dilakukan oleh keluarga menunjukkan hasil yang baik (Tabel 2). Dari hasil observasi yang dilakukan setelah pelatihan diperoleh data bahwa mayoritas keluarga dapat mempraktikkan keterampilan yang telah diajarkan dengan benar. Mereka dapat mengajarkan senam kaki dan pengaturan nutrisi bagi lansia yang berpenyakit kronis. Data wawancara menunjukkan bahwa keluarga merasa sangat terbantu dengan informasi perihal cara merawat lansia di rumah. Hal itu juga meningkatkan kepercayaan diri mereka dalam melaksanakan tugas dan perannya sebagai caregiver. Hasil evaluasi pelaksanaan tugas perawatan kesehatan keluarga juga menunjukkan bahwa sebagian besar keluarga telah dapat melakukan tugas perawatan kesehatan dengan baik (Tabel 2).

Tabel 2 Tingkat Pengetahuan dan Tugas Perawatan Kesehatan Keluarga

\begin{tabular}{clcc}
\hline No. & \multicolumn{1}{c}{ Keterangan $(\mathbf{n}=\mathbf{1 9})$} & Jumlah & Persentase \\
\hline 1. & Pengetahuan (nilai, mean \pm sd) (nilai 1-10) & \multicolumn{2}{c}{$8.63 \pm 0.955$} \\
2. & Tugas Perawatan Kesehatan Keluarga & \multicolumn{2}{c}{} \\
& Baik & 14 & 73.6 \\
& Kurang & 5 & 26.4 \\
\hline
\end{tabular}

Sumber: Data primer diolah (2018)

Tugas perawatan kesehatan keluarga terdiri atas lima aspek utama, yaitu keluarga mampu mengenali masalah, keluarga mampu mengambil keputusan yang tepat mengenai kondisi keluarga yang sakit, keluarga mampu merawat anggota keluarga yang sakit, keluarga mampu memodifikasi lingkungan, dan keluarga mampu memanfaatkan fasilitas layanan kesehatan (Maglaya, 2009). Kelima tugas tersebut merupakan bagian 
dari fungsi keluarga yang bertujuan untuk memaksimalkan kondisi kesehatan anggota keluarga dan mempertahankan kebiasaan pola hidup sehat dalam keluarga.

Pelatihan dengan metode pengajaran keterampilan perawatan dan pemberian modul mengenai perawatan lansia di rumah dengan sakit kronis dapat meningkatkan pengetahuan dan kemampuan keluarga. Hal itu merupakan langkah yang tepat agar keluarga dapat belajar secara langsung dan dapat mempelajari kembali pengetahuan yang telah didapatkan. Hasil evaluasi pelatihan menunjukkan bahwa peserta memiliki nilai rata-rata pengetahuan yang baik, yaitu 8.63 (pertanyaan pre-test dan post-test memiliki skor maksimal 10). Data pencapaian lima tugas perawatan keluarga setelah pelatihan juga menunjukkan hasil yang baik. Berdasarkan data tersebut diketahui bahwa 14 dari 19 keluarga $(73,6 \%)$ mendapatkan hasil baik (mandiri dalam melakukan kegiatan perawatan) berdasarkan penilaian observasi home visit, sedangkan lima keluarga yang lain $(26,4 \%)$ mendapatkan nilai kurang karena masih memerlukan bimbingan dan bantuan pada saat dilakukan home visit. Hal ini menujukkan bahwa pelatihan dapat meningkatkan kemampuan seseorang dalam bidang tertentu. Lima tugas kesehatan keluarga sudah dapat dilaksanakan dengan baik oleh keluarga. Hal itu diketahui berdasarkan hasil evaluasi yang dilakukan selama satu bulan setelah kegiatan. Keberhasilan tersebut didukung dengan adanya modul kesehatan yang dapat dibaca dan dicermati kembali oleh keluarga pada saat melakukan tindakan di rumah.

Rumah ramah lansia merupakan konsep membuat lingkungan rumah menjadi lingkungan yang aman untuk lansia serta mendukung peningkatan status kesehatan lansia. Lingkungan rumah yang dimaksud tidak hanya terbatas pada lingkungan fisik, namun juga lingkungan sosial berupa perhatian dan dukungan keluarga untuk memberikan perawatan yang optimal kepada anggota keluarga mereka. 


\section{SIMPULAN}

Kegiatan pelatihan pada keluarga dengan lansia sakit kronis ini dapat meningkatkan pengetahuan keluarga perihal melakukan perawatan kesehatan di rumah. Hal ini dibuktikan dengan meningkatnya nilai pre-test serta meningkatnya skor kemampuan keluarga dalam melakukan lima tugas perawatan kesehatan. Pendidikan kesehatan dan pelatihan keterampilan perawatan sederhana di rumah merupakan salah satu aspek penting yang harus diberikan kepada keluarga lansia yang sakit oleh tenaga kesehatan. Kerja sama dan dukungan dari masyarakat berupa partisipasi kader kesehatan posyandu lansia dalam membantu menyebarkan informasi kesehatan lansia dan mewujudkan keluarga yang peduli terhadap kesehatan lansia menjadi salah satu faktor penting terwujudnya Rumah Ramah Lansia.

\section{DAFTAR PUSTAKA}

Amigo, T.A.E. (2012). Hubungan Karakteristik dan Pelaksanaan Tugas Perawatan Kesehatan Keluarga Dengan Status Kesehatan Pada Agregate Lansia Dengan Hipertensi di Kecamatan Jetis Yogyakarta (Tesis tidak dipublikasikan). FIK UI, Jakarta.

Arbaiyah. (2008). Performance Of Caregiver in Taking Care Of Mental Illness Patient in Family in Aceh Tamiang District, NAD, Indonesia (Tesis tidak dipublikasikan). Mahidol University. Thailand.

Alvarez, I.C.C., Ong, M.B., \& Abocejo, F.T. (2017). Learning Needs and Quality Care Among Family Caregivers and Elderly Patients of Guadalupe, Cebu City, Central Philippines. European Scientific Journal, (13)24: 1857-7431.

Asniar, (2007). Studi Fenomenologi tentang Pengalaman Keluarga Merawat Anggota Keluarga Paska Stroke di Kelurahan Depok Kecamatan Pancoran Mas Kota Depok Jawa Barat (Tesis tidak dipublikasikan). FIK UI, Jakarta. 
Badan Pusat Statistik (BPS). (2018). Proyeksi Penduduk Indonesia 2015-2045 Hasil

Supas 2015. Jakarta: Badan Pusat Statistik

Badan Pusat Statistik (BPS). (2018). Statistik Penduduk Lanjut Usia Tahun 2018. Jakarta: Badan Pusat Statistik.

Badan Pusat Statistik (BPS). (2018). Provinsi Jawa Timur Dalam Angka 2018. Badan Pusat Statistik Provinsi Jawa Timur.

BPS Provinsi Jawa timur. (2019). Statistik Daerah Provinsi Jawa Timur 2019. BPS Provinsi Jawa Timur. PT Sinar Murni Indo Printing.

Friedman, M.M., Bowden, V.R., \& Jones, E.G. (2010). Family Nursing: Research, Theory and Practice. Connecticut: Appleton \& Lange.

Goldzweig, G., Merims, S. Ganon, R. Peretz, T., \& Baider, L. (2012). Coping and Distress Among Spouse Caregivers to Older Patients With Cancer: An Intricate Path. Science Direct. Diunduh dari https://doi.org/10.1016/j.jgo.2012.07.003

Gopalan, N. \& Brannon L.A. (2006). Increasing Family Members' Appreciation of Family Caregiving Stress. Journal Psychology, 2006 Mar, 140(2):85—94.

Jaul, E. \& Barron, J. (2017). Age-Related Diseases and Clinical and Public Health Implications for the 85 Years Old and Over Population. Frontiers in Public Health, 5, 335. doi:10.3389/fpubh.2017.00335

Kementrian Kesehatan. (2018). Laporan Nasional Riskesdas 2018. Kementrian Kesehatan Republik Indonesia. Badan Penelitian dan Pengembangan Kesehatan.

Lee, Minhong. (2008). Caregiver Stress and Elder Abuse Among Korean Family Caregivers of Older Adults with Dissabilities. Journal of Family Violence, November 2008, 23:707. 
Maglaya, A.S. (2009). Nursing Practice in The Community. Marikina City: Argonauta Corp.

Pahlavanzadeh, S., Heidari, F.G., Maghsudi, J., Ghazavi, Z., \& Samandari, S. (2010). The Effects of Family Education Program on the Caregiver Burden of Families of Elderly with Dementia Disorders. Iranian Journal of Nursing and Midwifery Research, 15(3), 102-108.

Pemerintah Indonesia. (2017). Peraturan Menteri Sosial RI No 4 Tahun 2017. Jakarta.

Rosland, A.M. (2009). Sharing The Care: The Role of Family in Chronic Illness. California Healt Care Foundation. Diunduh dari https://www.chcf.org/wpcontent/uploads/2017/12/PDF-FamilyInvolvement_Final.pdf

Schulz R. \& Martire, L.M. (2004). Family Caregiving of Person With Dementia. American Journal Geriatric Psychiatry, 12(3): 240-249.

Shrestha, M. Heera, K.C., Bhattara, P., Mishra, A. \& Parajuli, S.B. (2018). Quality of Life of Elderly People Living With Family and in Old Age Home in Morang District, Nepal. Multidisciplinary Jounal of Science, Technology and Mathematics, ISSN 2091-0762.

Spillman B.C., Wolff J., Freedman V.A., \& Kasper J.D. Informal Caregiving for Older Americans: An Analysis of the 2011 National Study of Caregiving. Washington, DC: Office of the Assistant Secretary for Planning and Evaluation; 2014. [April 9, 2015]. Diunduh dari http://aspe.hhs.gov/report/informal-caregiving-older-americans-analysis-2011national-health-and-agingtrends-study

Wiyono, Joko. (2007). Studi Fenomenologi Pengalaman Keluarga Dalam Merawat Lansia Dengan Ketergantungan Tinggi di Rumah, Kota Malang Jawa Timur (Tesis tidak dipublikasikan). FIK UI, Jakarta. 
Wolff J.L., Spillman B.C., Freedman V.A., \& Kasper J.D. (2016). A National Profile of Family and Unpaid Caregivers Who Assist Older Adults with Health Care Activities. JAMA Internal Medicine, 2016, 176(3): 372-379.

Wu S.Y. \& Green A. (2000). Projection of Chronic Illness Prevalence and Cost Inflation. Washington DC: RAND Health. 